\title{
OS DIREITOS DA CRIANÇA E A ASSISTÊNCIA SOCIAL
}

\section{LES DROITS DE L'ENFANT ET L'ASSISTANCE SOCIALE}

Eni Maria Monteiro Barbosa *

BARBOSA, E.M.M. ( s direitos da Criança e a Assistência Social. Rev. Bras. Cresc. Des. Hum. 111(1): São Paulo, 1993.

\section{RESUMO}

Resultado do estabelecimento de uma nova ordem democrática, a Constituição de 1988 garante os direitos do cidadão e incentiva a participação da comunidade na execução das politicas sociais, especialmente aquelas voltadas para a proteção da infancia e da parcela da população menos favorecida. A assistência social passa a ter um conceito mais amplo: sua função inclui a proteção à familia, à maternidade, às crianças e à velhice.

A participação comunit ria é facilitada pelas diretrizes que normatizam a desccntralização, tanto no que se refere a elaboração, quanto à aplicação das politicas sociais do governo federal. Mas não existe ainda uma lei organica para regulamentar as recentes definições constitucionais e levá-las à prática. Falta interesse do Executivo, que teme uma $\operatorname{ref}^{\wedge} \mathrm{orm}^{\wedge} \mathrm{u}^{\wedge} \mathrm{la}{ }^{\wedge} c ̧ a ̃{ }^{\wedge} \mathrm{o}$ em seus quadros e na sua polltica centralizadora, além de ter de destinar mais recursos para a população carente.

\section{RÉSUMÉ}

Issue de l'instauration d'un nouvel ordre démocratique, la Constitution Brésilienne de 1988 garanti les droits du citoyen et appelle á la participation de la communauté dans l'exécution des politiques sociales, notamment celles qui visent la protection de l'enfance et de la couchc la plus démunie de la population. L'assistance sociale prend ainsi une conception plus amplo: sou rale inclu la protection de la famille, de la maternité, des enfants et de la vieillesse.

La participation communautaire est organisée par des directivos concernant la décentralisation de l'élaboration et de l'application des politiques sociales du gouvernement federal. Toutefois, il n'existe pas encore une loi qui réglemente les recentes définitions constitutionelles et qui les mette en pratique. Un plus grand intêrét de la pari du pouvoir exécutif fait défaut car il, qui craint une reform^^ $\sim$ lation de ses objectifs et de sa politique centralisatrice, ainsi qu’une augmentation du budget destiné aux populations démunies.

* Assistente Social, Mestre em Educação, Chefe da Assessoria de Planejamento da LBA - Diretoria Nacional.

End.: SQS 110 - Bloco E - apto. 602 - Brasília/DF - Brasil - CEP 70373-050. 
No início dos anos oitenta o país atravessou um difícil ciclo econômico em que os indicadorcs sociais, que vinham mostrando tendências constantes de melhora, passam a expressar estagnação ou pioras visIveis. Estas constatações se fizeram simultaneamente a amplo movimento social de luta pela redemocratização do país, culminando, os dois processos, no comprometimento da Nação e do Estado com a busca de estratégias de resgate da chamada dívida social brasileira.

As políticas sociais, e no seu interior as de assistência social e da infancia, são reconhecidas como tendo fundamental importancia no esforço que o pais deveria empreender para dinninuir as intensas desigualdades sociais e minorar os efeitos da pobreza que atingia amplos segmentos da população.

Para que essas politicas cumprissem efetivamente seu papel, seria necessário remover alguns dos problemas que vinham sendo correntemente diagnosticados.

Os estudos apontavampara uma atuação pública "residual em termos de recursos e fragmentada em termos de suas ações. Inexistia uma política que claramente definisse seus objetivos, limites e clientela, o que conduzia à existência de um conjunto de 6rgãos e programas desarticulados, adotando metodologias inadequadas ao trato conseqücnte e eficaz dos problemas sociais aos quais se dirigiam, com algumas ações necessárias inexistentes e redundantes em outras, constituindo-se o espaço privilegiado de concentração dos vícios conhecidos que afetam a condução das pohticas públicas brasileiras: o clientelismo, o patrimonialismo e o assistencialismo.” (1).

Do ponto de vista jurídico-institucional, a nova Constituição Brasileira, promulgada a 5 de outubro de 1988, constitui um “divisor de águas” na área social. Forjada no ambito dos dois marcos aqui referidos - a implantação de nova ordem democrática e o resgate da divida social - confere à questão da participação e dos direitos sociais do cidadão (e conseqüentemente às politicas públicas da área social) a maior relevàneia Entre elas, aquelas voltadas especificamente à infancia e aos pobres, que aqui, nos interessam mais diretamente.

\section{As inovações constitucionais}

São vários os aspectos novos trazidos pela Constituição na área de Assistência Social, começando pela sua colocação como direitos social dos cidadãos.

A Constituição também avança na tentativa de conceituar e delimitar o campo da AssistEncia Social, definindo-a como a política devida a quem dela necessitar, independente de contribuição à seguridade social, e tendo como objetivos: a proteção à familia, à maternidade, à infancia, à adolescência e à velhice; o amparo às crianças e adolescentes carentes; apromoção da integração aomercado de trabalho; a habilitação e a reabilitação do deficiente e sua integração social; e a garantia de um saláriomínimo de benefício mensal a idosos e deficientes sem condições de auto-manutenção.

Do ponto de vista da organização da área, a nova Carta traz, também, grandes avanços em relação à prática atual, que se expressam nas diretrizes de descentralização e participação comunitária.

A concepção de "participação comunitária na formulação e no controle das ações em todos os níveis”, confomme a Constituição, é sensivel avanço sobre a prática então dominante, onde funciona principalmente como mecanismo de transferência de responsabilidade do Estado para as comunidades, muitas vezes significando a simples exploração de mão-de-obra comunitária, e uma forma perversa de cooptação elou desmobilização popular.” (2)

\section{A regulamentação pós-constituinte}

Essas grandes definições constitucionais relativas à Assistência Soeial deveriam ser regulamentadas em lei espec fica e levadas à prática. Infelizmente, o pa s não dispõe ainda hoje de Lei Organica da Assistencia Social LOAS. Aproposta que tramitou foi de iniciativa do Legislativo, sendo vetada integra^lmente pela Presidência da República em setembro de 1990. (3)

A matéria volta à pauta do Legislativo em abril de 1991, também por iniciativa parlamentar. O Ministério da Ação Social tem um projeto elaborado, mas ainda não $\mathrm{o}^{\wedge}$ ficialmente encaminhando ao Congresso pclo Executivo.

Duas ordens de motivos parecem explicar 0 desinteresse do Executivo no encaminhamento do projeto. De um lado o quadro institucional e as práticas dos órgãos federais que terão que ser radicalmente revistos. De outro, a regulamentação de benefícios continuados para idosos e deficientes, que exigirão recursos adicionais de obtenção improvável no quadro atual de contenção do gasto público.

A ausência da LOAS não tem facilitado mudanças na área. Mesmo assim, instituições como CBIA e LBA vêm buscando rever-se e adaptar-se ao novo arcabouço legal. A LBA, por exemplo, vem tentando redirecionar-se numa linha de especialização de sua ação em tomo dos segmentos sociais reconhecidos como os mais vulneráveis - a criança, o idoso e a pessoa portadora de deficiência - bem como empreender articulações 
com estados e municípios visando constituir parcerias que facilitem a transferência da execução direta de serviços ainda existentes na instituição e o processo efetivo de descentralização.

\section{Assistência Social e Infancia}

A Assistência Social é uma política pública que tem um recorte especifico. Volta-se aos necessitados, àqueles que não têm suas necessidades mínimas satisfeitos, ou dito de outra forma, às populações marcadas pelo signo da exclusão, destituição, pobreza (4).

Diferente das demais políticas que se organizam em torno de um tipo específico de proteção social conforme a natureza da necessidade educacional, sagitária, habitacional, alimentar e outras - a política de assistência social organizase em torno de uma população carente que tem uma ou várias necessidades básicas insatisfeitas.

Para cumprir seu papel, a área assistencial faz de tudo um pouco. E generalista no tipo de proteção e específica (ou seletiva) na clientela, enquanto as demais são específicas no tipo de proteção e genéricas (ou universalizantes) quanto à população (5).

Na trajetória da Assistência Social no Brasil, observa-se que ela foi se construindo a partir de problemas sociais que alcançavam maior gravidade e visibilidade sem que o Estado dispusesse de mecanismos próprios para seu enfrentamento. Com a crescente participação pública no campo social, a assistência é abordada de modo conjuntural, gerando formas de atenção à população excluída ainda não consideradas na agenda das políticas públicas reconhecidas como direito.

Como só recentemente a questão da infancia em idade pré-escolar deixa de ser exclusiva de suas famílias, tornando-se desafio da sociedade e do estado, é natural-que a assistência social, desde suas origens, tenha se preocupado com este segmento da população. As motivações variaram no tempo: ora o abandono, ora a mortalidade infantil, ora a necessidade de cuidados e proteção pela incorporação das mães no mercado de trabalho, ora a desnutrição infantil etc.

A história da Fundação Legião Brasileira de Assistência ilustra com perfeição estas observações. Desde sua origem, a assistência à infância foi prioridade na Instituição. No início desenvolveram-se ações menos estruturadas de atenção ao grupo materno-infantil, com ênfase na educação social seguiu-se um enfoque predominantemente $\mathrm{m} \sim$ dico-social - foram construídos postos de puericultura, maternidades e hospitais infantis; posteriormente desenvolveram-se programas de distribuição de leite em pó e complementos alimentares e constituiu-se uma rede de creches, fomentando esses serviços em todo o país.

À medida em que as necessidades atendidas pela assistência social vão se definindo como direitos universais, os serviços passam a ser responsabilidade das áreas especificas $\sim$ A rede de hospitais, maternidades e postos de puericultura da LBA foi incorporada ao SUS, os programas de alimentação passaram à responsabilidade do INAN e até a merenda escolar, que se iniciou na LBA, está, há décadas, integrada à rede de ensino. Reconhecida hoje em sua função basicamente educacional, a creche tende a ser absorvida entre as tarefas da área de educação, como alie já determina a Constituição de 1988.

\section{Os Direitos das Crianças}

Precisar o papel da Assistência Social no atendimento aos direitos infantis não é tarefa fácil hoje, até mesmo pela referida transição por que passa a área.

Alguns referenciais devem ser observados. Em primeiro lugar, os compromissos da Nação e do Estado que estão inscritos na Constituição e no Estatuto da Criança e do Adolescente. Entre eles: a criança é prioridade absoluta; a criança é sujeito de direitos; entre os direitos infantis consideram-se o direito à vida, à saúde, à educação, à alimentação, ao lazer, à cultura, a uma família, ao seu desenvolvimento integral, à proteção contra toda sorte de violência, exploração e maus tratos...; a criança tem direito à assistência desde a fase de sua concepção; a criança tem direito a creche e pré-escola; os direitos devem ser observados pela família, pela sociedade e pelo estado.

Pan segundo lugar, aqueles que descrevam a situação social em que vivem as crianças de 0 a 6 anos. Emrápidas pinceladas, pode-se dizer que hoje $50 \%$ delas vivem em família na faixa da pobreza; $30 \%$ têm alguma forma de desnutrição; $80 \%$ não têm acesso à creche e pré-escola; 60 em mil crianças nascidas vivas morrem antes de completar o primeiro aniversário; 58 vivem em domicílios sem condições adequadas de saneamento;

Estes breves e resumidos indicadores globais revelam que essas crianças, que representam, portanto, mais de metade da nossa população infantil, não têm suas necessidades básicas e seus direitos sociais atendidos, constituindo-se, por definição constitucional, demandatários potenciais (e possuidores de direitos) da Assistência Social.

\section{Abordagem da Assistência}

Costumam-se identificar na prática da assistência social capitalista, onde convivem os princípios contraditórios da rentabilidade económica (lógica da acumulação) e das necessidades sociais 
(Justiça social), duas modalidades básicas de atuação referidas como strito senso e tatu senso (6). A assistência social ao sentido estrito é aquela submetida à lógica da rentabilidade económica e por isso mesmo esvaziada em seu conteúdo de justiça social. E um fim em si mesma - o que muitos cha Iam de assistencialismo. Funcional ao sistema capitalista, sua principal tarefa é reparar danos causados pela injustiça social sem contudo impor limites a essa injustiça. Age por fora das políticas sociais básicas e se executa geralmente em ffrgãos assistenciais em paralelo às políticas básicas específicas, representando uma of erta geralmente pobre para a população pobre, buscando mais a acomodação de tensões e o controle social do que a efetiva integração social do cidadão.

Já a assistência social no sentido lato tem como princípio a supremacia do critério da necessidade social sobre o da rentabilidade económica. Instala-se no interior das políticas públicas "abalando seu elitismo com a sua proposta de universalizarão"; é um meio e não um fim em si própria, pois sua função é estender direitos sociais; é redistributiva porque se "pauta num jogo de soma zero na alocação do produto social”. Perpassa as políticas públicas buscando estender os mesmos serviços e bens à população marginalizada, sem constituir, portanto, um sistema diferenciado para os pobres. E muitas vezes identificada com a dita promoção social.

A construção de uma assistência social que seja efetiva Dente um direito de cidadania exige que se explore, ao máximo, a assistência latiu senso. Inclusive porque dispõe-se hoje, pelo menos no nível da proposição, de serviços e/ou programas que cobrem a quase totalidade das necessidades infantis, no ambito setorial. Urgente hoje, é a definição de ações que reduzam o grau acentuado de seletividade e exclusão social das políticas públicas. E da mesma forma, é importante a criação de mecanismos de integração das políticas sesoriais.

Neste sentido, a função básica da assistência social parece‘ser principalmente a mobilização de recursos e a articulação de ações voltadas a remover as dificuldades de absorção, pelas políticas básicas, da população pobre. A função executara de serviços específicos seria menos estimulada.

\section{Um Novo Perfil Profissional}

Para atuar nessa direção, o profissional da área assistencial deve ter domínio amplo das políticas sociais e programas em desenvolvimen to, dos recursos existentes que podem ser articulados para solução dos problemas em tela, das inadequações e pontos de estrangulamento presentes nos progra- mas e ações, que impedem a absorção dos grupos sociais pobres, bem como das dificuldades concretas da população em se incorporar às políticas básicas. Deve, além dessa formação de natureza mais generalista, ser dotado de capacidade para a articulação e negociações políticas. Dadas as inúmeras possibilidades de ação setenial os profissionais específicos de operação deverão ser identificados e qualificados de acordo com o nível tecnológico do próprio setor.

A ênfase no exercício da assistência social lato senso, por permitir uma ação mais estrutural e grau maior de resolutividade dos problemas sociais, não significa $\wedge 0$ abandono das formas de atuação de sentido estrito e corte emergencial e compensatório 0 quadro social do país exige 0 desenvolvimento de ações desta natureza.

Na tradição brasileira, alguns tipos de serviços têm sido deixados à responsabilidade do setor assistencial. Entre eles aqueles voltados à proteção de grupos especialmente vulneráveis do ponto de vista biológico e social: crianças abandonadas, portadoras de deficiências, vitimizadas. Os desnutridos, que até recentemente eram atendidos pelos 6rgãos assistenciais em paralelo ao SUS, têm sido deixados à responsabilidade principal do setor de saúde, bem como os cuidados primários de saúde que envolvem ainda instituições não-governamentais de corte assistencial. Os programas de adoção, colocação em lar substituto e outras formas de resolução dos diferentes problemas que afetam as crianças, constituem ações também consideradas típicas da área. Para a LBAdestaca-se o programa de creches.

Dado que a creche é um espaço de atenção integral à criança, os recursos humanos envolvidos devem ter formação especifica para as várias atividades desenvolvidas: alimentação, educação, recreação e cultura, cuidados básicos de higiene e saúde, detecção precoce de deficiências, educação social para a família e a comunidade, animação cultural, além das atividades de gestão e apoio.

Já nos referimos ao falo de que os registros da política social, no Brasil, mostram como moitas formas de proteçào à população pobre foram geradas no campo assistencial e depois incorporadas nas agendas das políticas publicas básicas. Comprometida, como foi visto, mais com uma clientela especial do que como um tipo de serviço, essa área não pode perder esse papel gerador de políticas. Os padrões das necessidades sociais são historicamente definidos variando em cada tempo e lugar. Novas necessidades, novas carcncias estão sempre surgindo e novas formas de solociona-las devem ser permanentemente boscadas. 


\section{Alternativas Assistenciais}

Os serviços convencionais já projetados como universalizantes têm, às vezes, custos elevados e sua implantação geralmente é lenta. Há que se buscar alternativas simplificadas que no curto prazo atinjam todas as crianças necessitadas. Estas alternativas atenderiam a algumas necessidades e direitos específicos. A simplicidade significaria 0 alcau^lce de poucos objetivos, não devendo ser confundida com improvisação e falta de qualidade Atividades assistenciais dirigidas à socialização, recreação, lazer, cultura, educação de pais para a atenção às crianças, entre outras, são da maior importância para o pleno desenvolvimento infantil.

Um destaque deve ser dado a necessidade de trabalhos sistemáticos com a família pobre. $\mathrm{Na}$ prática assistencial - e a creche pode ser um exemplo - visa-se muitas vezes apenas a atenção à criança, esquecendose que ela não é destacável de sua família e que é no espaço familiar (e mesmo comunitário) que as condições efetivas para seu desenvolvimento integral se completarão.

Um último aspecto a que gostaríamos de nos referir diz respeito às detemiinações da Constituição e do Estatuto da Criança e do Adoles-

\section{Referências Bibliográficas e Notas}

01. Utilizam-se, neste tópico, algumas idéias desenvolvidas pela autora em trabalho anterior. Ia: BARBOSA, E. M. M. O processo dc Regulamentação da Assistência Social: Avanços e Recuos. Brasília, IPEA, 1991 (Texto para discussão, $n^{\circ}$ 222). 02. Idem, ibidem, p. 6.

03. BRASIL. PRESIDÊNCIA DA REPUB LICA. Mensagem Presidencial n ${ }^{\circ} 672$ de 17 de Setembro de 1990, ao Presidente do Senado. cente relativas à descentralização para os municípios das ações de assistência social e de atenção à infância.

A exemplo do que vem sendo feito no Sistema Unico de SaúdeSUS - há todo um esforço a ser feito no sentido de dotar estados e municípios de capacitação para o planejamento, a organização e a execução de servic, os assistenciais voltados à criança de 0 a 6 anos. Nesse processo, os Conselhos Estaduais e Municipais de Defesa dos Direitos das Crianças poderão ter um papel fundamental, mas para isso deverão estar plenamente capacitados. As equipes técnicas dos Grgãos federais, por sua vez, deverão estar capacitados à nova função que lhes cabe: coordenarão, noi^ Tnatização, assessoramento técnico e financeiro às equipes locais que assumirão a tarefa executiva.

Em conclusão, caberia dizer que a questão dos recursos humanos na área da atenção à infancia é fundamental, em especial no espaço de transitoriedade atual da área de Assistência Social. Mas ela envolve mais do que a capacitação dos operadores de serviços, pois afeta também a própria condição do sistema assistencial de adequar-se ao status novo de política pública e de direito de cidadania.

04.FALCÃO, M. C. B. C.- A política de Asa ia Social e o papel da FLB A. In: Semináno "A Política de Assistência Social no Brasil”, Brasília, LBA, 23 - 25110/91.

05. PEREIRA, P. A. P. A Assistencia Social como Garantia de Direitos; crítica aos equívocos conceituais e políticos. Brasília, UNBINEPPOS, 1989 (mimeo).

06. Toma-se emprestado a PEREIRA, P. A. P. op. cit. a maior parte das idéias usadas para caracterizar estas modalidades de atuação da assistência social. 